Published in final edited form as:

Ann Intern Med. 2018 November 20; 169(10): 684-693. doi:10.7326/M18-1250.

\title{
Smoking and Lung Cancer Mortality in the US from 2015-2065: a comparative modeling approach
}

\author{
Jihyoun Jeon, $\mathrm{PhD}^{1}$, Theodore R. Holford, $\mathrm{PhD}^{2}$, David T. Levy, $\mathrm{PhD}^{3}$, Eric J. Feuer, $\mathrm{PhD}^{4}$, \\ Pianpian Cao, $\mathbf{M P H}^{1}$, Jamie Tam, $\mathrm{PhD}^{5}$, Lauren Clarke, $\mathbf{M S c}^{6}$, John Clarke, $\mathbf{M S c}^{6}$, Chung \\ Yin Kong, $\mathrm{PhD}^{7,8}$, and Rafael Meza, $\mathrm{PhD}^{1,{ }^{*}}$ \\ ${ }^{1}$ Department of Epidemiology, School of Public Health, University of Michigan, 1415 Washington \\ Heights Ann Arbor, Ml 48109-2029 \\ ${ }^{2}$ Department of Biostatistics, Yale University, P.O. Box 208034, 60 College Street, New Haven, CT \\ 06520-8034 \\ ${ }^{3}$ Lombardi Comprehensive Cancer Center, Georgetown University, 615 N. Wolfe Street, \\ Baltimore, MD 21205 \\ ${ }^{4}$ Division of Cancer Control and Population Sciences, National Cancer Institute, 9609 Medical \\ Center Drive, Bethesda, MD 20892 \\ ${ }^{5}$ Department of Health Management and Policy, University of Michigan, 1415 Washington \\ Heights, Ann Arbor, Ml 48109-2029 \\ ${ }^{6}$ Cornerstone Systems Northwest Inc., Lynden, WA, 8665 Berthusen Rd., Lynden, WA 98264 \\ ${ }^{7}$ Institute for Technology Assessment, Massachusetts General Hospital, 101 Merrimac St., STE \\ 1010, Boston, MA 02114 \\ ${ }^{8}$ Department of Radiology, Harvard Medical School, 25 Shattuck Street, Boston, MA 02115
}

\begin{abstract}
Background: Tobacco control efforts implemented since the 1960s in the US have led to considerable reductions in smoking and smoking-related diseases including lung cancer.

Objective: To project the reduction in tobacco use and lung cancer mortality due to existing tobacco control efforts from 2015 to 2065.

Design: Comparative modeling approach using four lung cancer natural history simulation models that explicitly relate temporal smoking patterns to lung cancer rates.
\end{abstract}

\footnotetext{
*Corresponding Author Rafael Meza, 1415 Washington Heights, Ann Arbor, Michigan 48109, rmeza@umich.edu.

"This is the prepublication, author-produced version of a manuscript accepted for publication in Annals of Internal Medicine. This version does not include post-acceptance editing and formatting. The American College of Physicians, the publisher of Annals of Internal Medicine, is not responsible for the content or presentation of the author-produced accepted version of the manuscript or any version that a third party derives from it. Readers who wish to access the definitive published version of this manuscript and any ancillary material related to this manuscript (e.g., correspondence, corrections, editorials, linked articles) should go to Annals.org or to the print issue in which the article appears. Those who cite this manuscript should cite the published version, as it is the official version of record."
}

Disclosures: There are no conflicts of interest to disclose. 
Setting: US population, 1964-2065.

Participants: Adults ages 30-84.

Measurements: Models were developed using US smoking (1964-2015) and lung cancer mortality (1969-2010) data. Each model projected lung cancer mortality by smoking status assuming current declines in smoking continue into the future. Sensitivity analyses were conducted comparing optimistic and pessimistic assumptions relative to the status quo.

Results: Under the status quo scenario, age-adjusted lung cancer mortality is projected to drop 79\% from 2015 to 2065. Concomitantly, and despite the expected US population growth, aging and longer life expectancy, the annual number of lung cancer deaths is projected to decrease from 135,000 to 50,000 (63\% reduction). Nonetheless, 4.4 million deaths from lung cancer are still projected to occur in the US from 2015-2065, with about 20 million adults of ages 30-84 continuing to smoke in 2065.

Limitations: Projections assume that under the status quo, there are no changes to tobacco control efforts in the future, and do not explicitly consider the potential impact of lung cancer screening.

Conclusion: Tobacco control efforts since the 1960's will continue to reduce lung cancer rates well into the next half century. Additional prevention and cessation efforts are required to sustain and expand these gains, and further reduce the lung cancer burden in the US.

\section{Introduction}

Lung cancer mortality has decreased considerably in the US since the 1990s. Yet, it remains the leading cause of cancer death, accounting for about 1 in 4 cancer deaths in 2017 (1). Since publication of the first Surgeon General's Report (SGR) on smoking and health in 1964 (2), tobacco control programs and policies, including mass media campaigns, restrictions on youth access to tobacco, smoke-free air policies, and tobacco excise taxes have been implemented in the US. These efforts have been successful in reducing tobacco use and decreasing smoking-related morbidity and mortality (3-8).

Although it is expected that smoking and tobacco related diseases will continue to decrease, the precise impact that tobacco control policies implemented since the 1960s until today will have on future smoking and tobacco-related outcomes is unknown. In particular, although the lung cancer burden in the US is declining $(9,10)$, it is unclear how long this decline will continue for and at what rate. Improved knowledge of the future burden of lung cancer will aid in resource planning and evaluation, and in assessing the potential impact of additional tobacco control efforts, such as regulations to reduce the nicotine levels of cigarettes (11) or raising the minimum legal sale age for tobacco products (12) and other cancer prevention strategies, such as lung cancer screening $(13,14)$.

Simulation models have been a valuable tool for quantifying the impact of tobacco control policies on future smoking trends in the US (15) and worldwide (16), and projecting the impact of such efforts on smoking-related health outcomes $(5,6,8)$. For example, model projections have found that approximately 800,000 lung cancer deaths were averted among US adults aged 30-84 between 1975-2000 because of reduced tobacco smoking. However, 
this represents only $32 \%$ of lung cancer deaths that could potentially have been avoided during that period (5). Moreover, it has been estimated that about 8 million smoking-related deaths (including lung cancer deaths) were prevented from 1964-2012 due to tobacco control efforts, (6) but that about 17.7 million individuals still died prematurely during that period due to smoking. More recently, modeling analyses have suggested that raising the minimum legal age for purchasing tobacco products would lead to substantial reductions on smoking-related mortality in the US by 2100 (12), and that price related tobacco control policies may greatly reduce smoking attributable deaths, especially among low socioeconomic status groups (17).

In this paper, we apply four simulation models of smoking and the natural history of lung cancer to project lung cancer mortality in the US from 1964-2065, and to estimate the corresponding annual attributable fraction of lung cancer deaths due to smoking. As baseline, we assumed that current patterns (trends) of smoking initiation, cessation, and intensity by birth cohort remain fixed and stable into the future, i.e., a status quo scenario. We also performed sensitivity analyses with higher or lower future smoking initiation, cessation, and intensity rates compared to the status quo. Projections of the future burden of smoking and lung cancer can serve as a point of reference as new developments take place that could influence risk, such as changes to patterns of lung cancer screening or increased use of novel nicotine products like e-cigarettes. Future assessments of the impact of new prevention and treatment strategies require such status quo estimates as a basis for comparison.

\section{Materials and Methods}

\section{Models}

Four independent lung cancer natural history models were developed by investigators at four institutions within the Cancer Intervention and Surveillance Modeling Network (CISNET) lung cancer consortium (18): Georgetown University (GT), Massachusetts General Hospital and Harvard Medical School (MGH-HMS), University of Michigan (UM), and Yale University (YU). Modeling groups collaborated closely to establish common model inputs and define model analyses and scenarios. Descriptions of each of the models are provided below and in the Supplementary Note. We refer to these collectively as the CISNET-Lung models.

\section{Smoking History Generator}

Based on the National Health Interview Survey (NHIS), the Cancer Prevention Studies I \& II (CPS-I \& CPS-II), and the Human Mortality Database (HMD), the smoking history generator (SHG) is a micro-simulator that generates detailed individual smoking histories for the US population $(5,19)$ and provides these shared inputs for all CISNET-Lung models: rates of smoking initiation, cessation, cigarettes per day consumption, and death from nonlung cancer causes (e.g., other cancers, cardiovascular disease, and chronic obstructive lung disease) by age, birth cohort, and sex (Appendix Figure 1) (5,12,19-23). An earlier version of the SHG (19) was extended to consider NHIS data from 1964-2015. Simulated smoking 
prevalence using the SHG is consistent with that observed in the US through 2016 (Figure 1) $(23,24)$.

Initial smoking cessation efforts are often not successful with a high rate of relapse in the first two years after quitting $(25,26)$, so the SHG reclassified individuals in NHIS as current smokers at their reported age at quitting if they quit smoking less than two years before the interview (about 13\% of former smokers in the NHIS sample); otherwise they were classified as former smokers. Thus, current smokers in the SHG include those who have quit within the last two years, and the probability of becoming a former smoker represents those who have not smoked for more than two years, assuming successful permanent cessation.

\section{Projection of smoking patterns and life expectancy to 2065}

Each CISNET-Lung model projects age-specific lung cancer mortality rates from 19642065 in the US under specific smoking scenarios. For the status quo scenario, we assumed that current US population smoking patterns (initiation, cessation and intensity by age, sex and period), resulting from tobacco control efforts since the 1960s, the tobacco industry promotion efforts, and the underlying susceptibility of population among other factors, will continue into the future. In this scenario, the SHG uses smoking initiation, cessation and intensity rates by birth cohort, age, and sex estimated from age-period-cohort (APC) models (23) fitted to the observed smoking patterns from the 1964-2015 NHIS data (Appendix Figure 2). Appendix Figures 3-5 show the resulting age-specific smoking initiation, cessation, intensity rates (cigarettes per day), and smoking prevalence. We also projected life expectancy at age 40 for both women and men based on the Lee-Carter method, forecasting age-specific mortality rates by smoking status, and using the SHG simulated smoking prevalence $(12,22,27)$. (See Supplementary Note).

Sensitivity analyses considered two alternative scenarios: optimistic and pessimistic. For the optimistic scenario, we assumed $20 \%$ lower initiation rates, $20 \%$ higher cessation rates, and $20 \%$ lower mean cigarettes per day intensities for future birth cohorts after 1997 compared with the rates in the status quo scenario. Conversely, for the pessimistic scenario, we assumed 20\% higher initiation rates, 20\% lower cessation rates, and 20\% higher mean cigarettes per day intensities.

\section{Smoking dose-response module}

Using the SHG simulated individual smoking history and age at death from causes other than lung cancer for the US population, each CISNET-Lung model independently applies these simulated data to estimate annual age-specific lung cancer mortality as a function of smoking history, sex, and birth year in their own (smoking to lung cancer) dose response module. The dose-response modules for three models (GT, UM, YU) use a version of the two-stage clonal expansion model (TSCE) (28-30) that is a mechanistic model based on a biological paradigm of initiation, promotion, and progression of cell events during carcinogenesis, which incorporates accumulation of genetic or epigenetic mutations in stem cells and clonal expansion of partially altered cells on the pathway to malignancy $(28,29,31-$ 33). Although three models use the TSCE model as dose-response module, each group uses it with a different parameterization. The GT model uses parameters derived from fitting it to 
the Cancer Prevention Study II (CPS II) data (28), while the UM and the YU models use parameters obtained from fitting the TSCE model to the Nurses' Health Study (NHS) and Health Professionals' Follow-up Study (HPFS) cohort data (29). The MGH-HMS model uses a set of logistic regression models and tumor progression functions calibrated to SEER registry data, published cohort studies, and clinical trial data as dose-response module $(34,35)$. All the models incorporate multiple factors characterizing an individual's agespecific smoking history, such as age of smoking initiation, smoking intensity, and age of smoking cessation (for former smokers).

The MGH-HMS and the UM models utilized individual SHG smoking histories as inputs to simulate individual lung cancer outcomes (micro-simulation models), while the GT and the YU models used aggregated cross-sectional smoking prevalence estimates by calendar year and age stratified by smoking status and sex to simulate population-level lung cancer rates (macro-simulation models). All models computed annual cross-sectional lung cancer mortality rates by sex, age, and smoking status. A brief description for each model is provided in Table 1. More details available in the Supplementary Note.

\section{Calibration and Validation}

First calibrated to US lung cancer mortality from 1969-2000, the CISNET-Lung models successfully reproduced observed lung cancer mortality from 2001-2010 (Appendix Figure 6).

Model calibration for secular temporal trends-The models were calibrated further to match observed US lung cancer mortality rates for 1969-2010, by incorporating multiplicative factors that adjust for additional variation of lung cancer risk by year of death (period effects) and year of birth (cohort effects) (36). Models UM and YU adjusted for both period and cohort effects, while models GT and MGH-HMS adjusted only for cohort effects. All models then projected their estimated period and/or cohort effects into the future to adjust their lung cancer mortality projections, thus indirectly accounting for factors and trends not directly captured in the models solely based on current and future smoking. The fully calibrated models were then used for projecting lung cancer mortality from 1964-2065. Additional details provided in the Supplementary Note.

\section{Estimation of population attributable fraction}

We use the simulated lung cancer mortality rates by smoking status to estimate/project the population attributable fraction (PAF) of lung cancer mortality due to smoking from 1964 to 2065 (37). The PAF measures the fraction of lung cancer deaths that could have been avoided if no smoking had occurred:

$$
\text { PAF }=\frac{\operatorname{Pr}(\text { lung cancer death })-\operatorname{Pr}(\text { lung cancer death } \mid \text { never smokers })}{\operatorname{Pr}(\text { lung cancer death })}
$$

\section{Results}

Figure 1 shows smoking prevalence and its effect in the US from 1964-2065 based on simulated smoking histories from the SHG. Figure 1(a) shows observed adult smoking 
prevalence (ages 18-84) by sex from the NHIS, and the SHG-projected smoking prevalence under the status quo scenario from 1964-2065. Figure 1(b) shows the corresponding data and projections restricted to ages 30-84. The SHG simulations match well with the observed US prevalence from NHIS from 1965 to 2016. Because recent birth cohorts have lower smoking initiation and cessation rates, the projections show that a status quo scenario that remains constant into the future at the level estimated for recent birth cohorts will result in a falling annual prevalence until those from earlier cohorts are removed from the population, at which point the prevalence flattens out. Figure 1(c) shows corresponding projected life expectancy at age 40 for both women and men. The results show that at current trends, life expectancy at age 40 is expected to increase from 38.97 years in 2015 to 45.64 in 2065 in US men, and from 42.72 in 2015 to 48.21 in 2065 in US women.

\section{Lung cancer mortality projections}

Under the status quo scenario, all four CISNET-Lung models project that lung cancer mortality in the US will decrease considerably in the next decades, with a rapid decline until 2040, slowing down thereafter. Figure 2 shows the mean (across models) age-adjusted lung cancer mortality rate (AAR) per 100,000, with shaded area representing the range of the estimates over the four models. Model-specific results are shown in Appendix Figure 7.

Table 2 presents the AARs for selected years. The overall AAR is 65.0 in 2015 (78.3 men; 54.2 women), projected to decrease to 13.9 in 2065 (13.4 men; 14.4 women). This represents a $79 \%$ decrease from 2015 to 2065 for both men and women combined, with a greater reduction in men (83\% men; $73 \%$ women). Notably, the projected AARs for women and men become nearly the same by 2045 . The mean number of lung cancer deaths across the models is about 135,000 in 2015 (74,000 men; 61,000 women), projected to decrease to about 50,300 in 2065 (23,400 men; 26,900 women). This corresponds to a $63 \%$ decrease (68\% men; 56\% women). In total, the models project that about 4.4 million lung cancer deaths (2.2 million in men and 2.2 million in women) will occur in the US from 2015-2065.

Figure 3 shows as an example, projections from one of the four models (UM model) of the population of ages 30-84 and the corresponding number and proportion of lung cancer deaths by smoking status from 1964-2065 under the status quo scenario. Similar figures by sex (Appendix Figures 9-10), and for other models (Appendix Figures 11-14) are provided in the Supplementary Note. Qualitatively, all models consistently show a decreasing proportion of lung cancer deaths occurring among current smokers. For the exemplary model (Figure 3), the percentage of lung cancer deaths among current smokers would be $17.4 \%$ ( $21.7 \%$ men; $12.6 \%$ women) in 2065, which represents a reduction of 52\% (47\% men; 59\% women) compared to 2015. Despite the projected reductions in smoking prevalence, the simulations suggest that under the status quo there will be still about 20 million smokers of ages 30-84 in the US in 2065 .

\section{Sensitivity Analyses}

The results under the alternative more intensive (optimistic) and less intensive (pessimistic) tobacco control scenarios are provided in the Supplementary Note (Appendix Figure 8 and Appendix Table 1). Since these two alternative scenarios do not differ from the status quo 
scenario until the 1997 birth cohort, the differences in lung cancer outcomes are not apparent until later years. With more intensive tobacco control efforts (optimistic), assuming lower initiation, higher cessation, and lower mean cigarettes per day intensities for future birth cohorts relative to status quo scenario, the AAR would be 12.2 per 100,000 in 2065, which is about $12 \%$ lower than in the status quo scenario $(13.9$ per 100,000$)$. In this scenario the number of lung cancer deaths is projected to be 44,500 in 2065 , which is about $11.7 \%$ lower compared to the status quo scenario $(50,400)$. In contrast, under the pessimistic scenario, the AAR and the number of lung cancer deaths would be 16.0 per 100,000 and 58,200 in 2065, respectively, which are about $15.1 \%$ and $15.5 \%$ higher compared to the status quo scenario, respectively.

\section{Population attributable fraction}

All models projected considerable decreases in the proportion of lung cancer deaths attributable to smoking (PAFs). Figure 4 shows the mean (across models) and model ranges of the estimated PAF from 1964-2065. The mean PAF in 2015 is about $88 \%(85 \%-91 \%)$ for men and $79 \%(70 \%-86 \%)$ for women, decreasing to $58 \%(49 \%-68 \%)$ for men and $44 \%(34 \%-60 \%)$ for women in year 2065.

\section{Discussion}

Four independent lung cancer natural history models were developed to project lung cancer mortality rates for US men and women from 1964-2065, i.e., since the publication of the landmark 1964 Surgeon General's Report (SGR) on smoking and health. This analysis builds on our previous studies that estimated the number of lung cancer deaths (5) and tobacco-related deaths (6) prevented by tobacco control in the US during the first 50 years since the SGR.

Although the four CISNET-Lung models have different structures and use different data sources, all predicted the observed lung cancer mortality rates in the US from 1969 to 2010 well. Under the status quo scenario, all models consistently project considerable decreases in lung cancer mortality (AAR) from 2015-2065 with a concomitant reduction in number of lung cancer deaths. Moreover, the results suggest that the existing disparities in lung cancer by sex will disappear by the mid-2040s, when lung cancer rates will become roughly equal between women and men. This reflects the convergence in smoking behaviors between men and women as current cohorts with similar smoking patterns by sex become the bulk of the smoking population.

The models project continued decline in lung cancer mortality dating back to the 1990s. These projections result from the status quo assumptions that smoking patterns (initiation/ cessation/intensity) will remain at current levels for future cohorts. As past cohorts with higher smoking rates gradually drop out from the population, adult (aged 30-84) smoking prevalence declines from $19.7 \%$ in 2015 ( $21.6 \%$ men; $17.8 \%$ women) to $7.5 \%$ in 2065 (8.9\% men; $6.0 \%$ women). The large reduction in lung cancer mortality during the next halfcentury occurs largely because of the lower initiation rates in current cohorts, leading to lower smoking prevalence at older ages when lung cancer risk is greatest. All models project considerable decline in lung cancer mortality rates and overall death counts from 2015-2065 
even under the conservative assumptions in the status quo and pessimistic scenarios, and despite the projected US population growth, aging, and the expected increases in life expectancy at age 40 of about 6.7 and 5.5 years for men and women, respectively.

Despite these gains, the models project that under the status quo scenario around 4.4 million lung cancer deaths will still occur in the US from 2015-2065, the majority among ever smokers, highlighting the need for additional efforts, such as lung cancer screening (13), to further reduce the burden of lung cancer. In fact, the models project that, under the status quo scenario or even if optimistically $20 \%$ better or pessimistically $20 \%$ worse, in 2065 about 20 million individuals aged 30-84 would still be current smokers, indicating that tobacco use would continue to be a major public health problem through the next half century.

This study is limited by status quo assumptions that do not explicitly consider the effects of changes in current smoking trends due to multiproduct use or changes to tobacco control efforts. For instance, additional changes in smoking rates might be triggered by the changing landscape of tobacco products, such as the recent introduction of alternative tobacco products like e-cigarettes $(38,39)$ and poly-tobacco use $(40,41)$. However, much of these changes appear to be reflected in recent birth cohorts, which have shown dramatic reductions in smoking rates in recent years $(42,43)$. These changes are reflected in the recent declines in smoking prevalence, which account for lower initiation rates. Moreover, given the lag between smoking exposure and lung cancer, changes that are mostly among more recent cohorts are unlikely to affect lung cancer rates until at least 30 years into the future. That future impact will depend on any effects of e-cigarette use on lung cancer, which is yet unknown. Similarly, major changes can also occur with the implementation of new tobacco control efforts, such as nicotine regulation (44).

Our sensitivity analyses of optimistic and pessimistic scenarios captures changes that could affect younger cohorts such as new product use or tobacco control interventions. We note that, although lung cancer screening is now being slowly adopted, changes to lung cancer screening could not only reduce lung cancer deaths, but could also increase smoking cessation if support for quitting is combined with screening at the point of care (45). Our projections will need to be updated as new information on cigarette and other tobacco product use becomes available.

A second limitation is that the models for lung cancer mortality only use smoking history, age and sex as risk factors, without considering other factors like exposure to second hand smoke, radon gas, asbestos or other carcinogens; family history; chronic obstructive pulmonary disease; occupational exposures; race and socioeconomic status (46-51). However, smoking is currently estimated to account for about $84 \%$ of lung cancer deaths in the US men and $81 \%$ in women (7), not including second hand smoke, indicating that smoking accounts for the overwhelming majority of lung cancer incidence and mortality. Moreover, our models do account for age-specific risk of lung cancer among never smokers, based on data from large prospective cohorts $(28,29,52)$. While these models primarily account for age and sex, several studies have shown that there are no major time trends in 
lung cancer risk among never smokers $(53,54)$, supporting our approach even in a future when the majority of lung cancers occur among non-smokers.

Another limitation is that the parameters built into each model's smoking dose-response module were estimated using specific cohort studies, such as NHS/HPFS or CPS-II, which may not be representative of the US population. To address these issues, model results were calibrated to observed lung cancer mortality in the US using period and/or cohort effects. These temporal effects were projected into the future to capture additional variations in lung cancer risk beyond smoking. Despite the use of different approaches to extrapolate these temporal adjustments across models, all model estimates agree well with observed lung cancer mortality in the US and result in consistent projections of lung cancer deaths through 2065.

This study is strengthened by the fact that each model was validated and provided reasonable 10-year predictions following the last available year of survey data used for calibration. Moreover, the largely consistent results across all models, despite their underlying differences, provide additional confidence in the projections through cross validation(55). In addition, the models directly incorporate detailed smoking histories, enabling each model to explicitly relate the complex dynamics of smoking initiation, cessation and intensity rates by age, cohort, calendar-year and sex into the projections of lung cancer mortality.

The results of this study provide a status quo reference for comparison with future trends in smoking and lung cancer mortality that may accompany expanded tobacco control policies. Moreover, our approach including multiple birth cohorts into model development provides a basis for assessing the potential of new tobacco control and other prevention strategies such as lung cancer screening among eligible individuals in the entire US population. Previous analyses by the CISNET lung group and the US Preventive Services Task Force assessed the benefits and harms of lung cancer screening on the 1950 birth cohort $(13,14)$. Further analyses will assess the impact on multiple US birth-cohorts, focusing on the effectiveness of screening for more recent birth cohorts than the 1950s, which have had a considerable lower exposure to smoking. Furthermore, these models will serve as a basis for assessing the combined impact of tobacco control programs and lung cancer screening on lung cancer risk, particularly of smoking cessation programs implemented within the context of lung cancer screening (45).

In summary, our analyses indicate that maintaining existing tobacco control efforts will deliver considerable reductions in lung cancer burden in the US. Our projections also highlight that smoking will continue to be an important determinant of lung cancer risk during this century. Continued policies and measures to discourage the uptake of smoking in youth and to promote cessation for current users are thus needed to retain the gains that have already been made, with additional efforts required to further decrease the toll of tobacco smoking on health. 


\section{Supplementary Material}

Refer to Web version on PubMed Central for supplementary material.

\section{Acknowledgments}

Role of the Funding Source

This study was funded by grants U01CA152956 and U01CA199284 from the National Cancer Institute, which had no role in the design or conduct of the study; collection, management, analysis, or interpretation of the data; preparation, review, or approval of the manuscript; or the decision to submit the manuscript for publication.

\section{References:}

1. American Cancer Society. Cancer Facts \& Figures 2017 Available from: https://www.cancer.org/ research/cancer-facts-statistics/all-cancer-facts-figures/cancer-facts-figures-2017.html Accessed 8/17 2018.

2. NIH. The Reports of the Surgeon General. The 1964 Report on Smoking and Health: Documents [Internet] [cited 2017 Apr 3]. Available from: https://profiles.nlm.nih.gov/ps/retrieve/ Narrative/NN/p-nid/60/p-docs/true

3. Thun MJ, Jemal A. How much of the decrease in cancer death rates in the United States is attributable to reductions in tobacco smoking? Tob Control 2006 10;15(5):345-7. [PubMed: 16998161]

4. Jemal A, Thun M, Yu XQ, Hartman AM, Cokkinides V, Center MM, et al. Changes in smoking prevalence among U.S. adults by state and region: Estimates from the Tobacco Use Supplement to the Current Population Survey, 1992-2007. BMC Public Health 2011 6;11:512. [PubMed: 21714876]

5. Moolgavkar SH, Holford TR, Levy DT, Kong CY, Foy M, Clarke L, et al. Impact of reduced tobacco smoking on lung cancer mortality in the United States during 1975-2000. J Natl Cancer Inst 20124 4;104(7):541-8. [PubMed: 22423009]

6. Holford TR, Meza R, Warner KE, Meernik C, Jeon J, Moolgavkar SH, et al. Tobacco control and the reduction in smoking-related premature deaths in the United States, 1964-2012. JAMA 20141 8;311(2):164-71. [PubMed: 24399555]

7. U.S. Department of Health and Human Services. The Health Consequences of Smoking-50 Years of Progress: A Report of the Surgeon General [Internet] Atlanta: U.S. Department of Health and Human Services, Centers for Disease Control and Prevention, National Center for Chronic Disease Prevention and Health Promotion, Office on Smoking and Health; 2014 [cited 2017 Jul 13]. Available from: https://www.surgeongeneral.gov/library/reports/50-years-of-progress/

8. Levy DT, Meza R, Zhang Y, Holford TR. Gauging the Effect of U.S. Tobacco Control Policies From 1965 Through 2014 Using SimSmoke. Am J Prev Med 2016 4;50(4):535-42. [PubMed: 26673484]

9. Rustgi AK. The genetics of hereditary colon cancer [Internet]. Vol. 21, Genes and Development 2007 [cited 2018 Aug 17]. p. 2525-38. Available from: https://www.cancer.org/research/cancerfacts-statistics/all-cancer-facts-figures/cancer-facts-figures-2017.html [PubMed: 17938238]

10. Meza R, Meernik C, Jeon J, Cote ML. Lung cancer incidence trends by gender, race and histology in the United States, 1973-2010. PLoS One 2015;10(3).

11. FDA's Plan for Tobacco and Nicotine Regulation. https://www.fda.gov/TobaccoProducts/ NewsEvents/ucm568425.htm.

12. Institute of Medicine (IOM). No Title [Internet] [cited 2017 Sep 15]. Available from: http:// nationalacademies.org/HMD/Reports/2015/TobaccoMinimumAgeReport.aspx.

13. Moyer VA, Force USPST. Screening for lung cancer: U.S. Preventive Services Task Force recommendation statement. Ann Intern Med 2014 3;160(5):330-8. [PubMed: 24378917]

14. De Koning HJ, Meza R, Plevritis SK, Ten Haaf K, Munshi VN, Jeon J, et al. Benefits and harms of computed tomography lung cancer screening strategies: A comparative modeling study for the U.S. Preventive services task force. Ann Intern Med 2014;160(5). 
15. Mendez D, Warner KE, Courant PN. Has smoking cessation ceased? Expected trends in the prevalence of smoking in the United States. Am J Epidemiol 19988 1;148(3):249-58. [PubMed: 9690361]

16. Mendez D, Alshanqeety O, Warner KE. The potential impact of smoking control policies on future global smoking trends. Tob Control 2013 1;22(1):46-51. [PubMed: 22535364]

17. Monograph 22: A Socioecological Approach to Addressing Tobacco-Related Health Disparities. No Title [Internet] [cited 2018 Mar 12]. Available from: https://cancercontrol.cancer.gov/brp/tcrb/ monographs/22/.

18. The Cancer Intervention and Surveillance Modeling Network (CISNET). No Title [Internet] [cited 2017 Sep 27]. Available from: https://cisnet.cancer.gov/

19. Jeon J, Meza R, Krapcho M, Clarke LD, Byrne J, Levy DT. Chapter 5: Actual and counterfactual smoking prevalence rates in the U.S. population via microsimulation. Risk Anal 2012 7;32 Suppl 1:S51-68. [PubMed: 22882892]

20. Feuer EJ, Levy DT, McCarthy WJ. Chapter 1:The impact of the reduction in tobacco smoking on U.S. lung cancer mortality, 1975-2000: an introduction to the problem. Risk Anal 2012 7;32 Suppl 1:S6-13. [PubMed: 22882893]

21. Anderson CM, Burns DM, Dodd KW, Feuer EJ. Chapter 2: Birth-cohort-specific estimates of smoking behaviors for the U.S. population. Risk Anal 2012 7;32 Suppl 1:S14-24. [PubMed: 22882884]

22. Rosenberg MA, Feuer EJ, Yu B, Sun J, Henley SJ, Shanks TG, et al. Chapter 3: Cohort life tables by smoking status, removing lung cancer as a cause of death. Risk Anal 2012 7;32 Suppl 1:S2538. [PubMed: 22882890]

23. Holford TR, Levy DT, McKay LA, Clarke L, Racine B, Meza R, et al. Patterns of birth cohortspecific smoking histories, 1965-2009. Am J Prev Med 2014 2;46(2):e31-7. [PubMed: 24439359]

24. Tam J, Levy DT, Jeon J, Clarke J, Gilkeson S, Hall T, et al. A study protocol for projecting the effects of tobacco control policies through microsimulation. BMJ Open 2018;8(3):e019169.

25. Krall EA, Garvey AJ, Garcia RI. Smoking relapse after 2 years of abstinence: findings from the VA Normative Aging Study. Nicotine Tob Res 2002 2;4(1):95-100. [PubMed: 11906685]

26. Hughes JR, Peters EN, Naud S. Relapse to smoking after 1 year of abstinence: a meta-analysis. Addict Behav 2008 12;33(12):1516-20.

27. Sprague WW. LCFIT (web based software for estimating the Lee-Carter method for modeling and forecasting mortality, with extensions to Coherent Forecasts of Li and Lee, and Lee-Carter method with sparse and incomplete data) [Internet] 2009 [cited 2018 Aug 17]. Available from: http:// lcfit.demog.berkeley.edu/

28. Hazelton WD, Clements MS, Moolgavkar SH. Multistage carcinogenesis and lung cancer mortality in three cohorts. Cancer Epidemiol Biomarkers Prev 2005 5;14(5):1171-81. [PubMed: 15894668]

29. Meza R, Hazelton WD, Colditz GA, Moolgavkar SH. Analysis of lung cancer incidence in the Nurses' Health and the Health Professionals' Follow-Up Studies using a multistage carcinogenesis model. Cancer Causes Control 2008 4;19(3):317-28. [PubMed: 18058248]

30. Hazelton WD, Jeon J, Meza R, Moolgavkar SH. Chapter 8: The fhcrc lung cancer model. Risk Anal 2012;32(SUPPL.1).

31. Moolgavkar SH, Jr AGK. Mutation and cancer: a model for human carcinogenesis. J Natl Cancer Inst 1981 6;66(6):1037-52. [PubMed: 6941039]

32. Little MP. Are two mutations sufficient to cause cancer? Some generalizations of the two-mutation model of carcinogenesis of Moolgavkar, Venzon, and Knudson, and of the multistage model of Armitage and Doll. Biometrics 1995 12;51(4):1278-91. [PubMed: 8589222]

33. Heidenreich WF, Wellmann J, Jacob P, Wichmann HE. Mechanistic modelling in large case-control studies of lung cancer risk from smoking. Stat Med 2002 10;21(20):3055-70. [PubMed: 12369081]

34. McMahon PM, Kong CY, Weinstein MC, Tramontano AC, Cipriano LE, Johnson BE, et al. Adopting helical CT screening for lung cancer: potential health consequences during a 15-year period. Cancer 2008 12;113(12):3440-9. [PubMed: 18988293] 
35. McMahon PM, Kong CY, Johnson BE, Weinstein MC, Weeks JC, Kuntz KM, et al. Estimating long-term effectiveness of lung cancer screening in the Mayo CT screening study. Radiology 2008 7;248(1):278-87. [PubMed: 18458247]

36. Holford TR. Understanding the Effects of Age, Period, and Cohort on Incidence and Mortality Rates. Annu Rev Public Health [Internet] 19915 [cited 2018 Jul 16];12(1):425-57. Available from: http://www.ncbi.nlm.nih.gov/pubmed/2049144

37. Bruzzi P, Green SB, Byar DP, Brinton LA, Schairer C. Estimating the population attributable risk for multiple risk factors using case-control data. Am J Epidemiol 1985 11;122(5):904-14. [PubMed: 4050778]

38. Cherng ST, Tam J, Christine PJ, Meza R. Modeling the Effects of E-cigarettes on Smoking Behavior: Implications for Future Adult Smoking Prevalence. Epidemiology 2016 Nov;27(6):81926. [PubMed: 27093020]

39. Chang JT, Levy DT, Meza R. Trends and Factors Related to Smokeless Tobacco Use in the United States. Nicotine Tob Res 2016 8;18(8):1740-8. [PubMed: 26995793]

40. Lee YO, Hebert CJ, Nonnemaker JM, Kim AE. Multiple tobacco product use among adults in the United States: Cigarettes, cigars, electronic cigarettes, hookah, smokeless tobacco, and snus. Prev Med (Baltim) 2014 5;62:14-9.

41. Lee YO, Hebert CJ, Nonnemaker JM, Kim AE. Youth tobacco product use in the United States. Pediatrics 2015 3;135(3):409-15. [PubMed: 25647680]

42. Wang TW, Gentzke A, Sharapova S, Cullen KA, Ambrose BK, Jamal A. Tobacco Product Use Among Middle and High School Students — United States, 2011-2017. [Internet] 2018 Available from: https://www.cdc.gov/mmwr/preview/mmwrhtml/mm6245a2.htm

43. Johnston LD, Miech RA, O’Malley PM, Bachman JG, Schulenberg JE, Patrick ME. Monitoring the Future national survey results on drug use: 1975-2017: Overview, key findings on adolescent drug use. [Internet] 2018 Available from: http://monitoringthefuture.org/pubs/monographs/mtfoverview2017.pdf

44. Apelberg BJ, Feirman SP, Salazar E, Corey CG, Ambrose BK, Paredes A, et al. Potential Public Health Effects of Reducing Nicotine Levels in Cigarettes in the United States. N Engl J Med 2018 3;378(18):1725-33. [PubMed: 29543114]

45. Kathuria H, Detterbeck FC, Fathi JT, Fennig K, Gould MK, Jolicoeur DG, et al. Stakeholder Research Priorities for Smoking Cessation Interventions within Lung Cancer Screening Programs. An Official American Thoracic Society Research Statement. Am J Respir Crit Care Med 2017 11;196(9):1202-12. [PubMed: 29090963]

46. Zhong L, Goldberg MS, Parent ME, Hanley JA. Exposure to environmental tobacco smoke and the risk of lung cancer: a meta-analysis. Lung Cancer 2000 1;27(1):3-18. [PubMed: 10672779]

47. Darby S, Hill D, Auvinen A, Barros-Dios JM, Baysson H, Bochicchio F, et al. Radon in homes and risk of lung cancer: collaborative analysis of individual data from 13 European case-control studies. BMJ 2005 1;330(7485):223. [PubMed: 15613366]

48. Nitadori J, Inoue M, Iwasaki M, Otani T, Sasazuki S, Nagai K, et al. Association between lung cancer incidence and family history of lung cancer: data from a large-scale population-based cohort study, the JPHC study. Chest 2006 10;130(4):968-75. [PubMed: 17035426]

49. Raviv S, Hawkins KA, Jr, Kalhan R. Lung cancer in chronic obstructive pulmonary disease: enhancing surgical options and outcomes. Am J Respir Crit Care Med 2011 5;183(9):1138-46. [PubMed: 21177883]

50. Markowitz SB, Levin SM, Miller A, Morabia A. Asbestos, asbestosis, smoking, and lung cancer. New findings from the North American insulator cohort. Am J Respir Crit Care Med 2013 7;188(1):90-6. [PubMed: 23590275]

51. O'Keefe EB, Meltzer JP, Bethea TN. Health disparities and cancer: racial disparities in cancer mortality in the United States, 2000-2010. Front public Heal 2015 4;3:51.

52. Meza R, Ten Haaf K, Kong CY, Erdogan A, Black WC, Tammemagi MC, et al. Comparative analysis of 5 lung cancer natural history and screening models that reproduce outcomes of the NLST and PLCO trials. Cancer 2014;120(11).

53. Thun MJ, Henley SJ, Burns D, Jemal A, Shanks TG, Calle EE. Lung cancer death rates in lifelong nonsmokers. J Natl Cancer Inst 2006 5;98(10):691-9. [PubMed: 16705123] 
54. Thun MJ, Hannan LM, Adams-Campbell LL, Boffetta P, Buring JE, Feskanich D, et al. Lung cancer occurrence in never-smokers: an analysis of 13 cohorts and 22 cancer registry studies. PLoS Med 2008 9;5(9):e185. [PubMed: 18788891]

55. Weinstein MC, O’Brien B, Hornberger J, Jackson J, Johannesson M, McCabe C, et al. Principles of good practice for decision analytic modeling in health-care evaluation: report of the ISPOR Task Force on Good Research Practices--Modeling Studies. Value Health 2003;6(1):9-17. [PubMed: 12535234] 

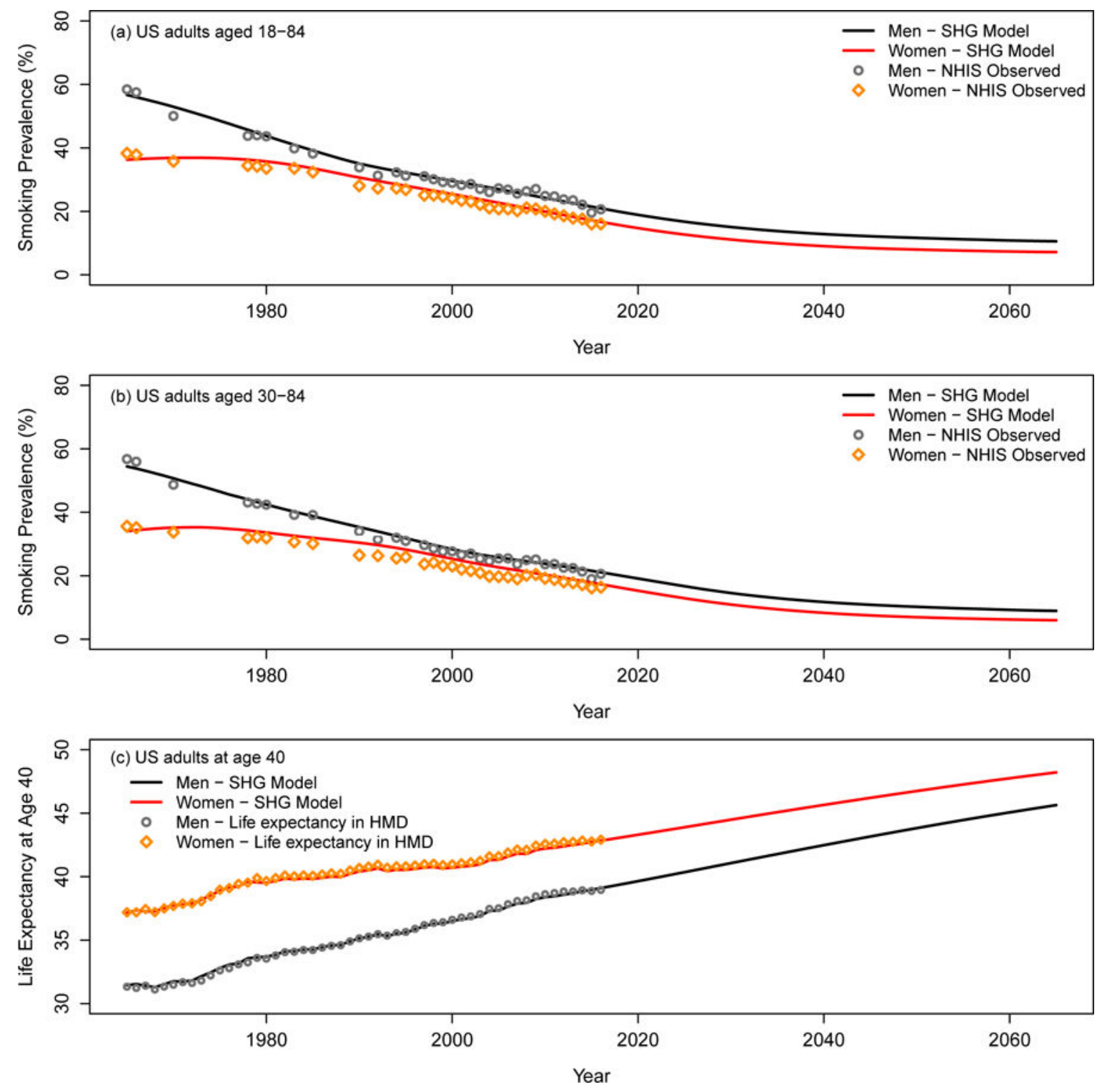

Figure 1.

Smoking prevalence among US adults. (a) and (b) Smoking prevalence for US men and women aged 18-84 and 30-84, respectively. The observed smoking prevalence (points) includes current smokers and former smokers who quit smoking less than 2 years in the NHIS data. The line represents the estimates based on simulated smoking histories for the US population by the SHG. The smoking prevalence was projected up to year 2065 under the status quo scenario. (c) Life expectancy at age 40 under the status quo scenario. The line represents the estimates based on simulated smoking histories for the US population by the SHG and projected US population based on the Lee-Carter model. The points represent the corresponding life expectancy in the Human Mortality Database (HMD) data. An interactive version of the figure can be found at https://resources.cisnet.cancer.gov/projects/\#shg/sbc2/ tool?figure=fig_1. 

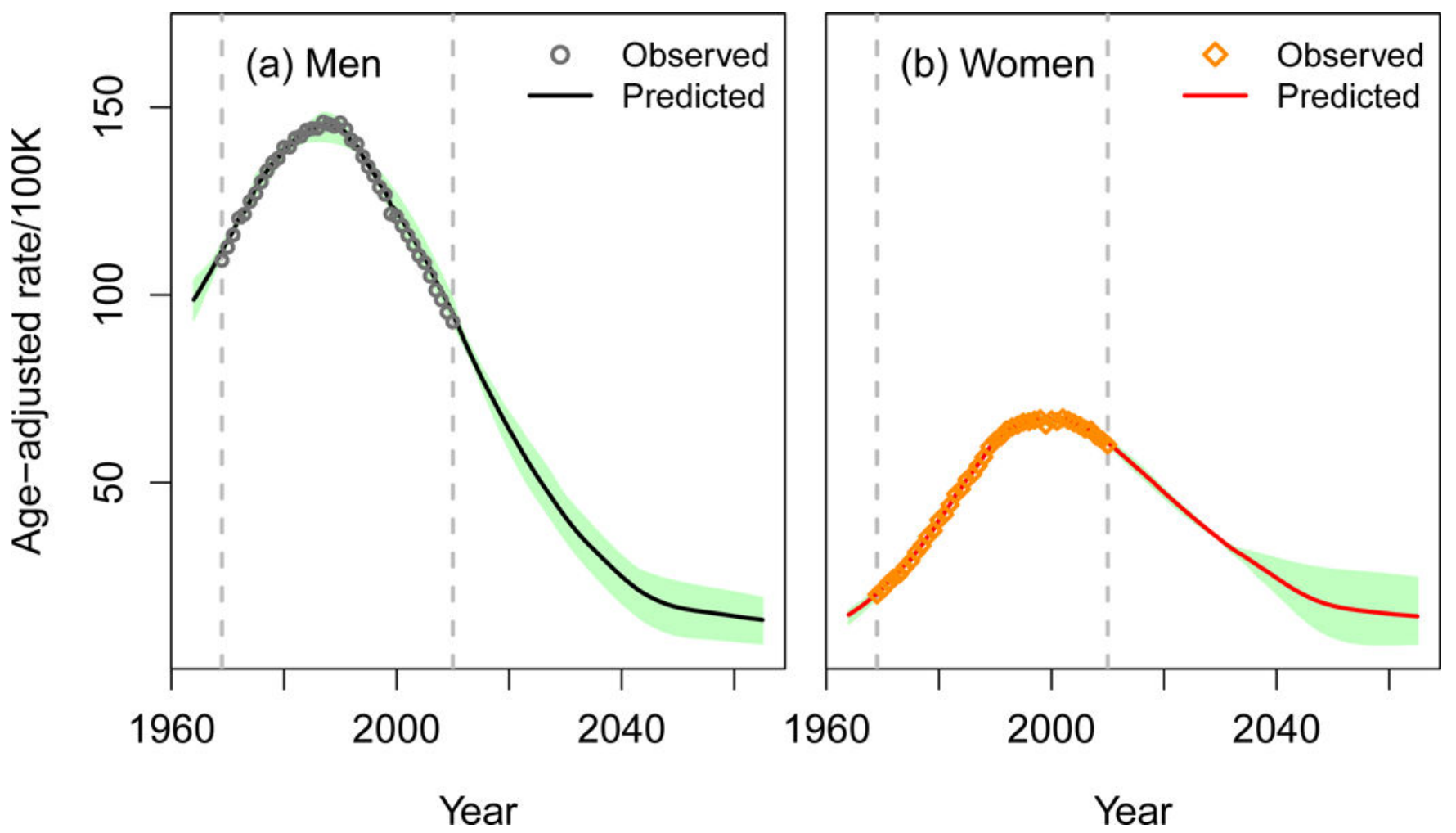

Figure 2.

Age-adjusted lung cancer mortality rates per 100,000 for 1964-2065 under the status quo scenario. The line represents the mean age-adjusted lung cancer mortality rate across four CISNET-Lung models, and the shaded area shows the range of age-adjusted lung cancer mortality rates per 100,000 across four models. The points represent the observed US lung cancer mortality rates for 1969-2010. The 2000 US population was used as the standard to calculate age-adjusted rates. An interactive version of the figure can be found at https:// resources.cisnet.cancer.gov/projects/\#shg/sbc2/tool?figure=fig_2. 

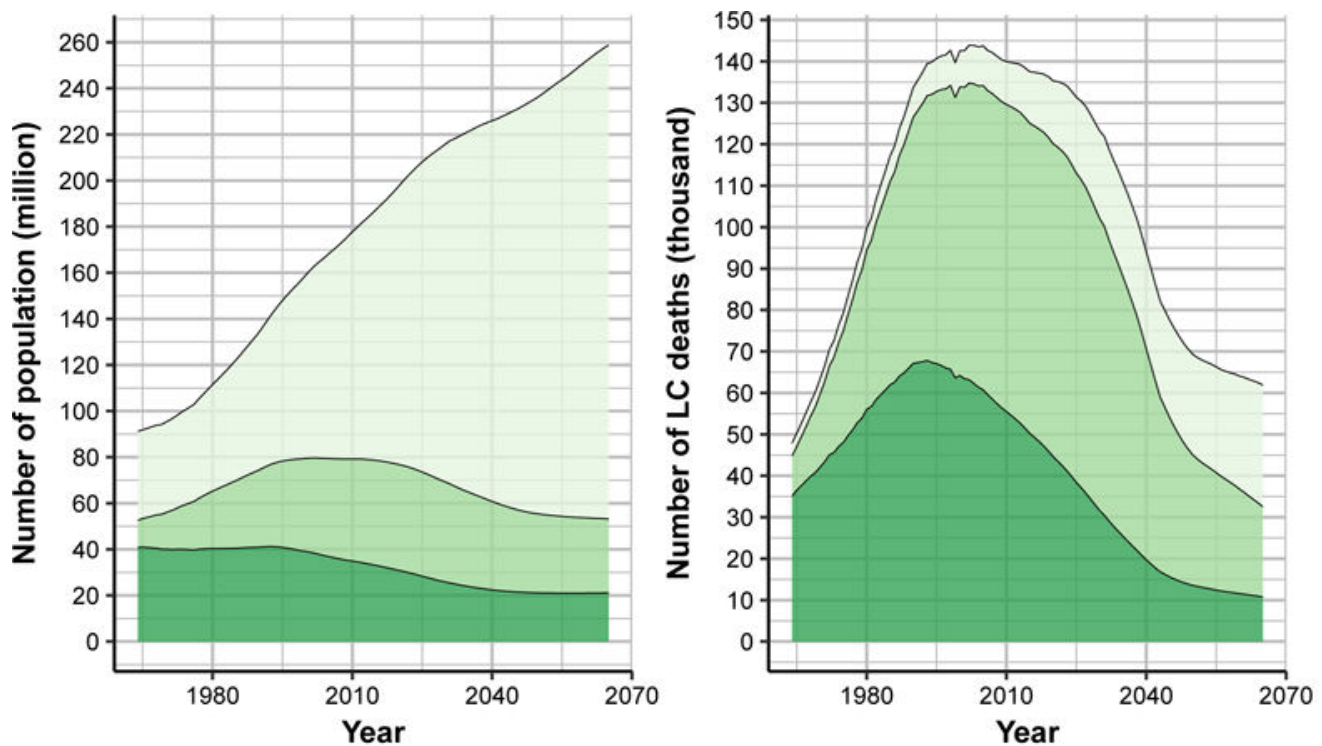

Status
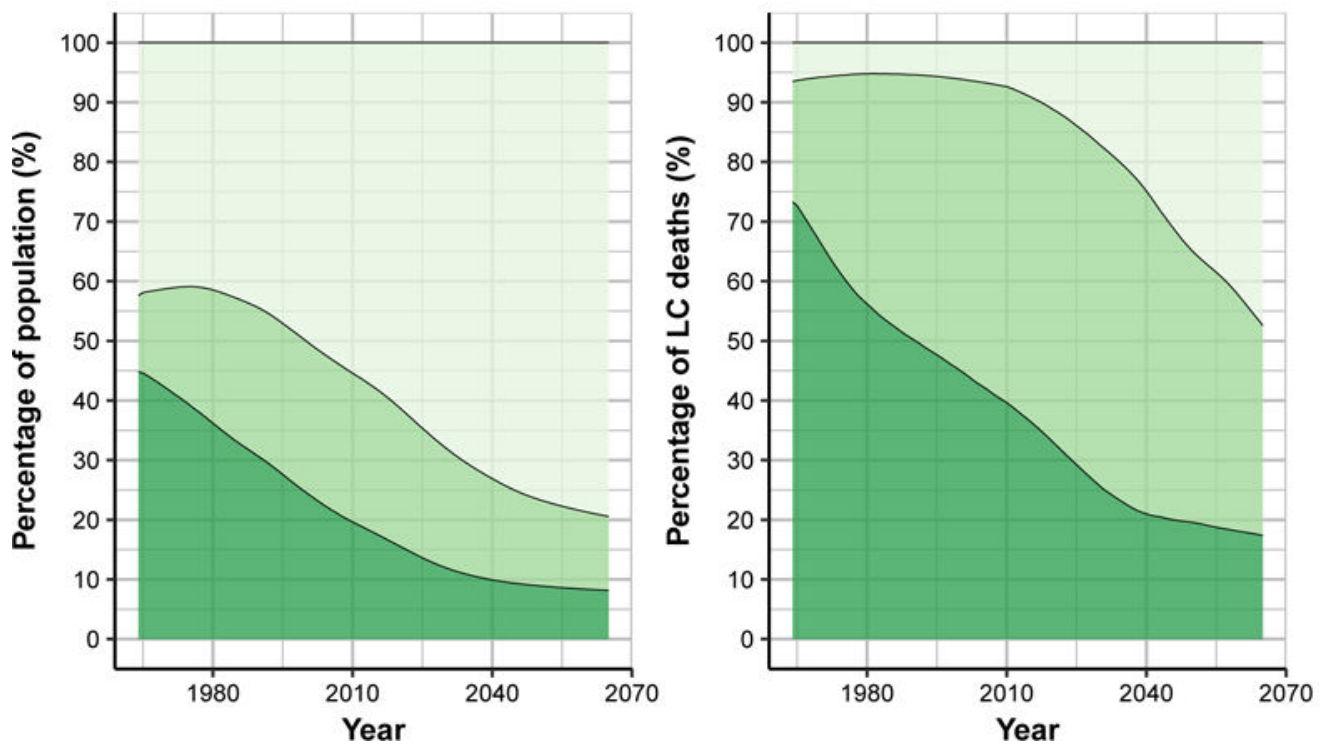

Never
Former
Current

Figure 3.

Population and lung cancer deaths from the University of Michigan (UM) model. Number and percentage of US population aged 30-84 by smoking status for 1964-2065 (left panels) and number and percentage of lung cancer deaths by smoking status for 1964-2065 (right panels), under the status quo scenario. An interactive version of the figure can be found at https://resources.cisnet.cancer.gov/projects/\#shg/sbc2/tool?figure=fig_3. 

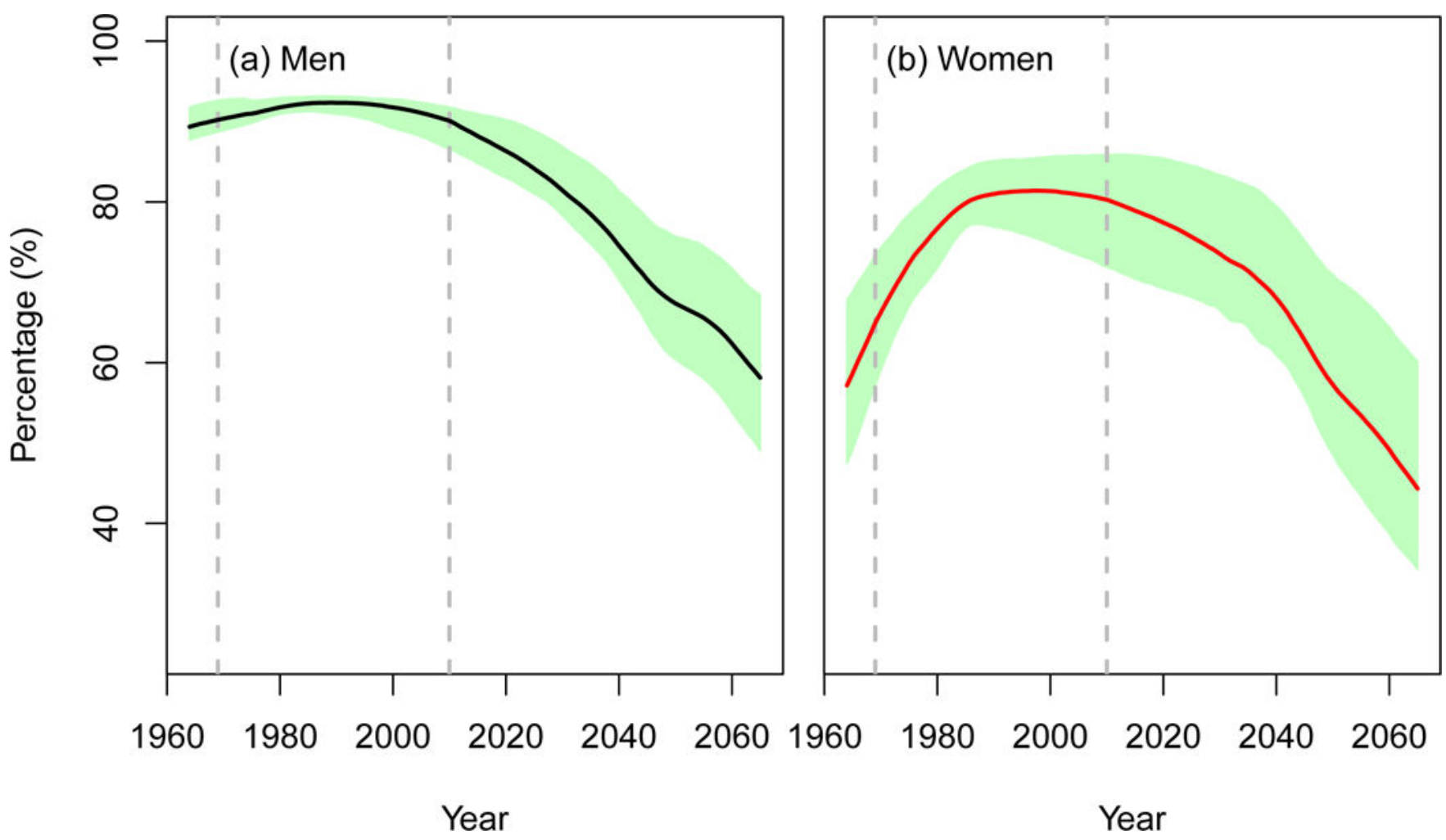

Figure 4.

Population attributable fraction (PAF) of lung cancer deaths due to smoking in the US for 1964-2065 under the status quo scenario. The line in the middle represents the mean PAF across four CISNET-Lung models. The shaded area shows the range of PAF estimates across four models. An interactive version of the figure can be found at https:// resources.cisnet.cancer.gov/projects/\#shg/sbc2/tool?figure=fig_4. 
Table 1.

Description of CISNET-Lung models.

\begin{tabular}{|c|c|c|c|c|}
\hline & GT & MGH-HMS & $\mathbf{U M}$ & $\mathbf{Y U}$ \\
\hline Institution & Georgetown University & $\begin{array}{l}\text { Massachusetts General Hospital- } \\
\text { Harvard Medical School }\end{array}$ & University of Michigan & Yale University \\
\hline $\begin{array}{l}\text { Original } \\
\text { motivation for } \\
\text { model } \\
\text { development }\end{array}$ & Policy evaluation & Screening evaluation & $\begin{array}{l}\text { Analysis of Epidemiological } \\
\text { data }\end{array}$ & $\begin{array}{l}\text { Population trend } \\
\text { effects on lung } \\
\text { cancer rates }\end{array}$ \\
\hline $\begin{array}{l}\text { Central smoking } \\
\text { dose-response } \\
\text { module }\end{array}$ & $\mathrm{TSCE}^{*}$ & Probabilistic/Logistic regressions & $\mathrm{TSCE}^{*}$ & $\mathrm{TSCE}^{*}$ \\
\hline $\begin{array}{l}\text { Calibration data } \\
\text { for dose-response } \\
\text { module }\end{array}$ & $\mathrm{CPS}^{\mathrm{II}^{\dagger}}$ (mortality) & SEER $^{+}$(incidence, survival) & $\mathrm{NHS}^{\mathcal{\xi}} \&$ HPFS $/ /$ (mortality) & $\underset{\text { (mortality) }}{\mathrm{NHS}^{\mathcal{\xi}} \& \mathrm{HPFS}^{/ /}}$ \\
\hline Unit of analysis & Macro-level/Group & Microsimulation /Individual & Microsimulation /Individual & Macro-level/Group \\
\hline $\begin{array}{l}\text { Lung cancer } \\
\text { Outcome } \\
\text { Calibration target }\end{array}$ & $\begin{array}{l}\text { US lung cancer } \\
\text { mortality }\end{array}$ & US lung cancer mortality & US lung cancer mortality & $\begin{array}{l}\text { US lung cancer } \\
\text { mortality }\end{array}$ \\
\hline $\begin{array}{l}\text { Temporal factors } \\
\text { for projection }\end{array}$ & Age-Cohort & Age-Cohort & Age-Period-Cohort & Age-Period-Cohort \\
\hline
\end{tabular}

* Two-Stage Clonal Expansion Model

${ }^{\dagger}$ Cancer Prevention Study II

Furveillance, Epidemiology, and End Results registry

$\xi_{\text {Nurses' Health Study }}$

/Health Professionals Follow-Up Study 
Table 2.

Mean (range in parenthesis) age-adjusted lung cancer mortality rates per 100,000 and number of lung cancer deaths in thousands under the status quo scenario over the four CISNET-Lung models for the US population (ages 30-84). The 2000 US population was used as the standard to calculate age-adjusted rates.

\begin{tabular}{|c|c|c|c|c|c|c|}
\hline & \multicolumn{1}{|c|}{ Age-adjusted lung cancer mortality rates/100,000 } & \multicolumn{2}{|c|}{ Number of lung cancer deaths (thousands) } \\
\hline Years & Men & Women & Both & Men & Women & Both \\
\hline 1965 & 101.1 & 15.8 & 54.7 & 43.9 & 7.8 & 51.7 \\
& $(96.6,105.6)$ & $(13.6,17.1)$ & $(52.9,57.2)$ & $(42.2,46.0)$ & $(6.7,8.4)$ & $(50.2,54.4)$ \\
\hline 1975 & 128.7 & 29.4 & 72.3 & 62.3 & 17.8 & 80.1 \\
& $(126.6,132.1)$ & $(28.6,30.4)$ & $(71.9,73.1)$ & $(61.6,64.0)$ & $(17.6,18.0)$ & $(79.3,81.6)$ \\
\hline 1985 & 144.2 & 50.9 & 90.5 & 80.2 & 36.5 & 116.7 \\
& $(141.0,146.5)$ & $(50.9,51.0)$ & $(89.1,91.6)$ & $(78.8,81.2)$ & $(35.9,36.8)$ & $(115.5,117.1)$ \\
\hline 1995 & 134.5 & 66.2 & 95.6 & 86.6 & 54.4 & 140.9 \\
& $(134.1,135.7)$ & $(65.7,66.9)$ & $(95.2,96.0)$ & $(86.2,87.2)$ & $(54.2,54.5)$ & $(140.7,141.4)$ \\
\hline 2005 & 110.0 & 65.3 & 85.0 & 83.4 & 61.2 & 144.5 \\
& $(106.6,114.4)$ & $(65.1,65.6)$ & $(83.8,86.7)$ & $(81.8,86.4)$ & $(61.1,61.2)$ & $(143.0,147.5)$ \\
\hline 2015 & 78.3 & 54.2 & 65.0 & 74.0 & 61.0 & 135.1 \\
& $(75.9,80.9)$ & $(52.8,55.6)$ & $(63.1,66.4)$ & $(71.0,76.4)$ & $(59.2,63.2)$ & $(130.2,137.5)$ \\
\hline 2025 & 51.6 & 40.9 & 45.7 & 64.8 & 60.8 & 125.6 \\
& $(45.6,57.7)$ & $(39.8,41.6)$ & $(42.4,48.9)$ & $(55.6,73.2)$ & $(57.8,63.1)$ & $(113.4,136.3)$ \\
\hline 2035 & 32.2 & 29.6 & 30.7 & 48.2 & 52.0 & 100.2 \\
& $(25.6,38.1)$ & $(27.7,31.7)$ & $(27.2,33.8)$ & $(38.4,57.1)$ & $(49.8,53.8)$ & $(88.2,110.8)$ \\
\hline 2045 & 19.6 & 20.0 & 19.8 & 29.9 & 35.2 & 65.2 \\
& $(12.2,25.7)$ & $(13.4,28.0)$ & $(14.5,26.4)$ & $(18.3,39.1)$ & $(26.2,47.5)$ & $(47.0,84.6)$ \\
\hline 2055 & 15.5 & 15.9 & 15.7 & 24.2 & 27.4 & 51.6 \\
& $(8.5,22.0)$ & $(7.1,26.2)$ & $(8.2,24.1)$ & $(12.9,34.7)$ & $(12.3,45.3)$ & $(27.1,79.8)$ \\
\hline 2065 & 13.4 & 14.4 & 13.9 & 23.4 & 26.9 & 50.4 \\
& $(7.1,19.3)$ & $(7.0,24.7)$ & $(7.8,22.0)$ & $(12.0,33.9)$ & $(13.2,46.5)$ & $(28.5,80.5)$ \\
\hline $2015-2065$ & 29.9 & 26.7 & 28.1 & $2,203.1$ & $2,238.2$ & $4,441.3$ \\
& $(23.9,35.4)$ & $(22.2,31.8)$ & $(24.4,31.5)$ & $(1755.9,2618.4)$ & $(1930.7,2616.7)$ & $(3815.3,4964.7)$ \\
\hline
\end{tabular}

